\title{
Nidificação e forrageamento de Centris (Ptilotopus) scopipes Friese (Hymenoptera, Apidae)
}

\author{
Maria Cristina Gaglianone ${ }^{1}$
}

\begin{abstract}
Nesting biology and foraging behavior of Centris (Ptilotopus) scopipes Friese (Hymenoptera, Apidae). Centris (Ptilotopus) are large bees and important pollinators in the Neotropical region. Its biology and behavior is still poorly known and only a few observations have been published. In this paper, observations on the biology of $C$. (Ptilotopus) scopipes Friese, 1899, a species that occurs in the "cerrados" of Brazil, are presented. The study was conducted in the Estação Ecológica de Jataí, in Luiz Antônio, São Paulo, during the active period of the adults (November through April). Females collected pollen from flowers of Solanaceae and Caesalpiniaceae, by vibration, and floral oils from Malpighiaceae belonging to the genera Byrsonima, Banisteriopsis, Stigmaphyllon and Peixotoa. Floral resources are carried in the hind leg scopae to the nests, which are excavated in the walls of epigeous nests of the termite Procornitermes araujoi Emerson, 1952 (Termitidae, Nasutitermitinae). The main tunnel entered the termite nest at an ascending angle ending in a vestibulum. Two parallel, vertical burrows forming linear series of cells descended from the vestibulum. The upper cell (the nearest to the nest entrance) was filled with soil. This might represent a protection against parasites. During the study, one female of Acanthopus excellens Schrottky, 1902 (Apidae, Ericrocidini), a cleptoparasitic bee, was captured when leaving one of the nests. A male of $C$. scopipes emerged eleven months after cell closure, suggesting a univoltine cycle for this species.

KEY WORDS. Centridini, cerrado, floral resources, Malpighiaceae, nests, phenology, termites
\end{abstract}

As abelhas do subgênero Ptilotopus Klug, 1810 distribuem-se desde o Panamá até o Brasil, onde ocorre a maior parte das espécies. No Brasil têm sido encontradas em áreas de cerrado (GOTTSBERGER \& GOTTSBERGER 1988; BARROS 1992; Silveira \& CAMPos 1995; Pedro 1996), caatinga (DuCKe 1908, 1910; MARTINS 1994; ZANELLA 2000), mata secundária (CURE et al. 1992; REBÊLO 1995) e em áreas alteradas, de pastagens abandonadas (SILVEIRA et al. 1993).

São abelhas de grande porte e, como a maioria dos Centridini, coletam óleos florais com estruturas especializadas localizadas nos basitarsos (VogEL 1974; NEFF \& SIMPSON 1981). Estudos sobre a biologia de C. (Ptilotopus) são restritos à nidificação de algumas espécies (C. sponsa Smith, 1854 - PICKEL 1928; LAROCA et al. 1993; C. derasa Lepeletier, 1841 - VesEY-FitzGERALD 1939; BENNETT 1964). Estes indicaram a associação de ninhos de C. (Ptilotopus) com termiteiros.

Centris scopipes Friese, 1899 foi registrada, na literatura, somente em áreas de cerrado do Distrito Federal (BARRos 1992), Minas Gerais (SILVEIRA \& CAMPOS

1) Pós-Graduação em Entomologia, Departamento de Biologia, FFCLRP, Universidade de São Paulo. Avenida dos Bandeirantes 3900, 14040-901 Ribeirão Preto, São Paulo, Brasil. E-mail: mcrisgag@usp.br 
1995) e São Paulo (GotTsberger \& GotTsberger 1988; Silveira \& CAmpos 1995). Além disso, foram examinados, para este trabalho, espécimens procedentes dos estados de Mato Grosso e Goiás (Coleção RPSP/Camargo). O comportamento dessas abelhas em flores de Bignoniaceae foi descrito por YANAGIZAWA \& GOTTSBERGER (1983), em área de cerrado no estado de São Paulo.

Neste trabalho serão apresentadas observações sobre a biologia de C. (Ptilotopus) scopipes, incluindo o período de atividade e fontes de recursos florais, comportamento e hábitos de nidificação, e sobre seu parasita, Acanthopus excellens Schrottky, 1902.

\section{MATERIAL E MÉTODOS}

O estudo dos ninhos foi realizado em março e abril de 1998, e as observações das abelhas nas flores, neste período e entre novembro/1998 e maio/1999, na Estação Ecológica de Jataí, em Luiz Antônio, São Paulo, Brasil. O clima da região é caracterizado como do tipo $\mathrm{Aw}$, segundo a classificação de Köppen, com verão quente e chuvoso e inverno frio e seco. A vegetação predominante é o cerrado, em diversas fisionomias, com parte da área ocupada por cerrado em recomposição.

Foram estudados dois ninhos com fêmeas em atividade e outros ninhos com células velhas localizados em dois termiteiros. As fêmeas nos ninhos foram marcadas com tinta no tórax, no dia anterior ao das observações. O comportamento das fêmeas nos ninhos e nas flores foi observado diretamente e através de filmagens em vídeo.

Os ninhos foram escavados e as larvas encontradas fixadas em solução Dietrich e conservadas em álcool $70 \%$. Os desenhos das larvas foram realizados sob lupa, com o auxílio de câmara clara.

\section{RESULTADOS}

\section{Local de nidificação e atividade das fêmeas nos ninhos}

Dois ninhos ativos de C. scopipes foram encontrados em termiteiro epígeo ativo, de Procornitermes araujoi Emerson, 1952 (Termitidae, Nasutitermitinae), que recebia insolação direta durante parte do dia. O termiteiro tinha $1 \mathrm{~m}$ de altura e as entradas dos ninhos das abelhas localizavam-se a $27 \mathrm{~cm}$ do solo, com cerca de $40 \mathrm{~cm}$ entre elas.

Os ninhos foram localizados em 16/3/1998, com uma fêmea em atividade em cada ninho. As fêmeas, marcadas, foram observadas no dia $31 / 3$, no período de 7:00 às 18:30 h. Saíram dos ninhos às 9:10 e 9:15 h, respectivamente, e fizeram cinco viagens, sempre voltando com pólen e óleo nas escopas e com grande quantidade de pólen espalhado por toda região ventral do corpo. Observações nas flores indicaram que a atividade das fêmeas iniciava antes do período de observações nos ninhos, por volta de 6:00h. A julgar pelo tempo gasto em cada viagem, é possível que as fêmeas tenham feito seis ou sete viagens no dia, e não somente as cinco viagens observadas. 
As viagens duraram entre 40 minutos e uma hora e 55 minutos (fềmea 1: 1h30min; 40min; 37min; 1h20min; 1h55min; fêmea 2: 1h50min; 1h05min; 58min; $1 \mathrm{~h} 20 \mathrm{~min} ; 1 \mathrm{~h} 10 \mathrm{~min})$ e, neste período, o ninho permanecia aberto. As fêmeas permaneciam nos ninhos de 8 a 20 minutos (fêmea 1: 10; 15;20;10; fêmea 2: 8; 8; 10; $9 \mathrm{~min}$ ), entre cada viagem de coleta. Por volta das 17:00 h, entraram nos seus respectivos ninhos, e intermitentemente por vários minutos, produziram um som de raspagem, porém, não foi possível observar a atividade dentro dos ninhos. Após esse período, as fêmeas permaneceram em silêncio e não saíram até o término das observações. Os ninhos não foram observados em 31/03 e 1/4; em 02/4 e dias subseqüentes as fêmeas não estavam presentes nos ninhos. O estudo da arquitetura indicou que estavam completos, com exceção do fechamento de uma galeria de células em um dos ninhos.

\section{Arquitetura dos ninhos}

A entrada, com contorno aproximadamente oval, apresentava largura de 1,0 a 1,5 cm e altura de 1,5 a $2,0 \mathrm{~cm}$. Seguia-se um canal principal aberto, ascendente, de mesmas dimensões da abertura de entrada, até $15 \mathrm{~cm}$ de extensão. A parede do canal era isolada do restante do termiteiro, sendo formada parcialmente pelas lâminas deste e parcialmente construída pelas abelhas. Cupins ativos foram vistos em túneis próximos às células de C. scopipes (Fig. 1), porém, sem comunicação com elas.

O canal principal terminava em um vestíbulo (Fig. 1), de onde saíam duas galerias verticais, descendentes, dispostas paralelamente e contendo, cada uma, uma série linear de duas a quatro células. $\mathrm{O}$ espaço entre duas células subseqüentes era de $2 \mathrm{~mm}$ e preenchido com terra.

As células apresentavam o maior diâmetro interno de 1,9 cm, inferiormente, e ápice truncado na região do opérculo, onde mediam $1,5 \mathrm{~cm}$. O comprimento externo variava de 2,8 a $2,9 \mathrm{~cm}$.

A parede das células (espessura de 0,9 a 1,6 $\mathrm{mm}$, sendo a região inferior mais espessa) estava firmemente aderida às paredes do termiteiro (Fig. 2); na sua face interna era coberta por um revestimento liso e homogêneo, de cerca de $0,2 \mathrm{~mm}$ de espessura, de material duro e brilhante, de coloração mélea, insolúvel em água. Externamente a essa camada, grãos de areia unidos por um material semelhante ao revestimento interno formavam a parede da célula. Com ação do calor, na chama, a parede tornava-se mais flexível e úmida, e os grãos de areia podiam ser mais facilmente separados da matriz.

O opérculo, côncavo internamente, apresentava uma espessura média de 1,6 $\mathrm{mm}$ e, centralmente, uma projeção externa de cerca de $0,95 \mathrm{~mm}$ de altura, sem abertura visível para o exterior. Acima do opérculo da célula superior, uma tampa fechava a galeria das células (Fig. 2).

A célula superior da galeria mais próxima à entrada do ninho não era revestida e estava preenchida com terra não compactada (Fig. 2). Em um dos ninhos, essa célula estava aberta, e, embora preenchida com terra, não havia a tampa de fechamento da galeria (veja próximo item e Fig. 5). 
Células velhas, de mesmo formato e tamanho, dispostas também em série vertical, foram encontradas próximo às recém-construídas; algumas tinham seu conteúdo totalmente mofado e outras apresentavam aberturas na parede, por onde as lâminas do termiteiro invadiam as células. Células velhas foram encontradas também em outros ninhos escavados de Procornitermes araujoi.

\section{Provisões e estágios imaturos}

Os ninhos foram abertos em 15/4/1998 e, nessa ocasião, as células continham larvas em diferentes estágios de desenvolvimento (Fig. 5). A galeria mais próxima à entrada do ninho continha as larvas mais velhas, em estágio pós-defecante, com casulo já tecido, que ocupava grande parte do espaço celular, sem alimento larval. A larva estava posicionada com o corpo dobrado, ficando as regiões anterior e posterior muito próximas, na parte inferior da célula (Fig. 2).

O casulo, de formato semelhante ao da célula, era formado por, pelo menos, três camadas fibrosas, facilmente destacáveis entre si. A mais externa, de coloração mélea a castanha, estava presa à parede da célula em toda sua extensão; a camada interna apresentava coloração palha e estava em contato com a larva. A espessura do casulo era maior na região basal das células, onde havia várias "pelotas" arredondadas e achatadas de fezes, entre as camadas do casulo (Fig. 2). Após defecar, a larva tece nova camada do casulo e sobre esta outras "pelotas" de fezes e nova camada, de forma que, após a defecação, não há contato da larva com as fezes. Na região superior da célula, inclusive opérculo, o casulo é fino e homogêneo, e acompanha a parede da célula.

Células localizadas na galeria mais distante da entrada do ninho continham larvas mais jovens (Fig. 5), sendo a mais jovem delas a da célula superior da galeria, posicionadas sobre uma massa de pólen de coloração amarelada, distribuída no fundo da célula e que, em seu volume total, chegava a 1/3 do volume interno da célula.

Em um dos ninhos, a galeria mais próxima da entrada possuía a célula superior preenchida com terra, embora aberta, não operculada e sem a tampa de fechamento (Fig. 5) e uma única célula aprovisionada com uma camada fina de substância líquida, oleosa, sobre a massa de pólen. O ovo do hospedeiro não estava presente e uma larva jovem, de parasita não identificado, estava na parede da célula.

Quatro células foram retiradas ainda fechadas e mantidas em laboratório. Em $02 / \mathrm{V}$, foi possivel observar o casulo tecido em uma das células, parcialmente aberta. Esta, porém, foi atacada por fungoš, ocasionando a morte da larva. Das células retiradas, apenas um macho emergiu, abrindo lateralmente a parede da célula, em 27/II/1999.

\section{Parasitas}

Fêmeas de Acanthopus excellens sobrevoavam as entradas dos ninhos, por vários dias consecutivos, ao longo do dia, durante a atividade de C. scopipes. Uma fêmea desse parasita foi coletada na entrada de um dos ninhos por volta de 13:00h, logo após ter entrado no canal principal, enquanto a fêmea de C. scopipes forrageava. 

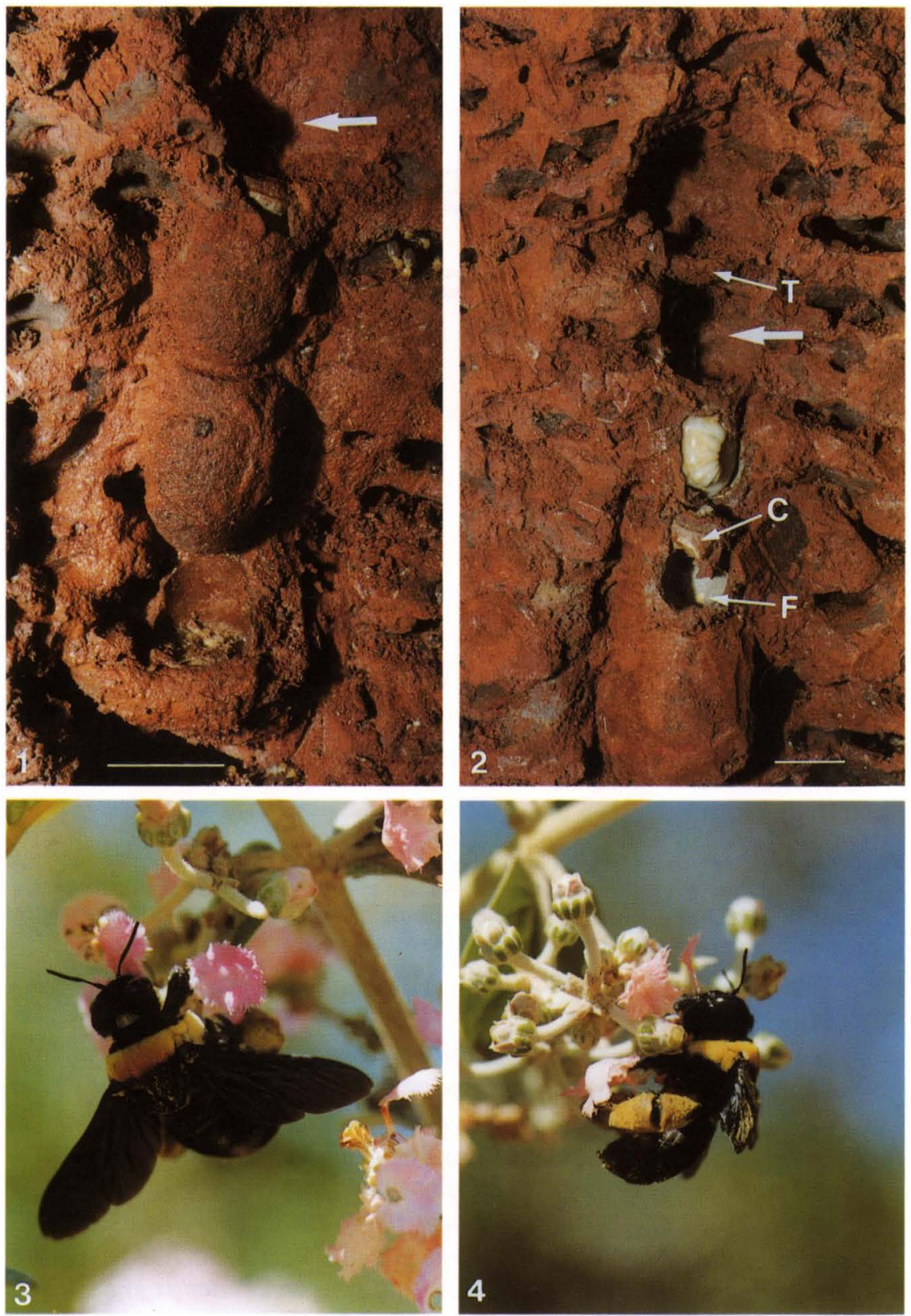

Figs 1-4. (1) Galeria de ninho de C. scopipes em termiteiro, com células dispostas verticalmente, uma delas aberta. Cupins ativos podem ser vistos próximos ao ninho da abelha. A seta indica a região vestibular, acima da galeria; (2) galeria com quatro células, a superior estava preenchida com terra (seta maior); (3) fêmea de C. scopipes em flor de Banisteriopsis malifolia (Malpighiaceae), coletando óleo; (4) idem anterior, escopa repleta de pólen. (T) Tampa superior que fecha a galeria, $(C)$ casulo, $(F)$ fezes. Escala $=2 \mathrm{~cm}$. 


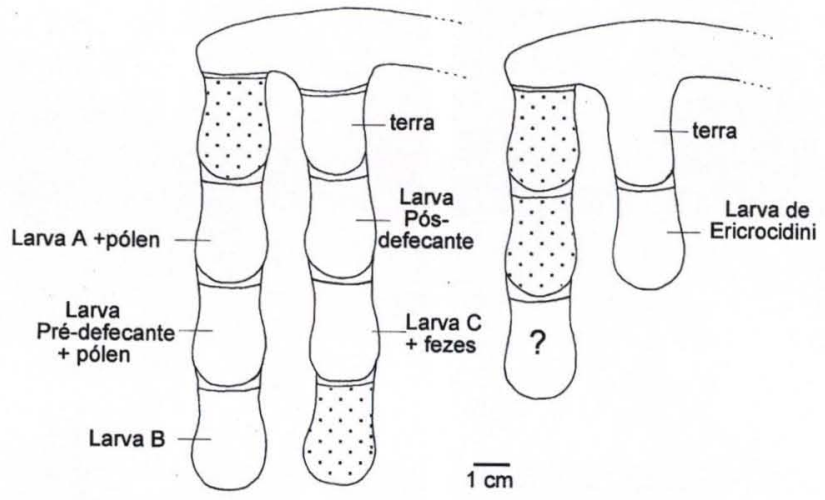

A

B

C
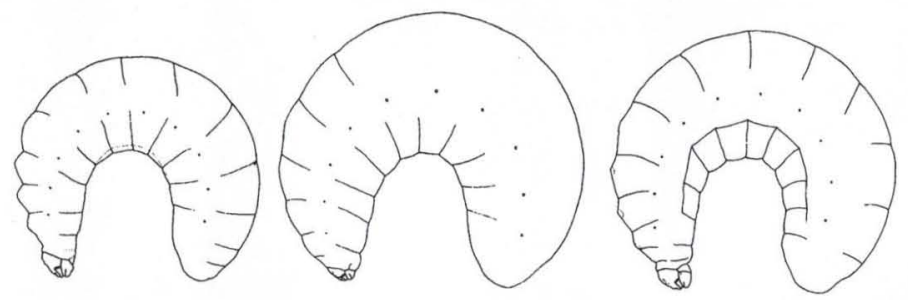

$1 \mathrm{~cm}$

Fig. 5. Esquema da disposição e conteúdo das células dos ninhos de $C$. scopipes estudados. Células pontilhadas no esquema foram mantidas fechadas, em laboratório, para emergência. As larvas de $C$. scopipes encontradas estão esquematizadas ( $A$ e $B=$ larvas pré-defecantes, $C=$ pós-defecante) e sua localização indicada no esquema dos ninhos.

\section{Atividade nas flores}

Fêmeas e machos de $C$. scopipes foram observados nas flores no período de novembro a abril, sendo fevereiro e março os meses de maior abundância.

A única forma de coleta de pólen pelas fêmeas foi a vibração, em flores de Solanum lycocarpum St. Hil. (Solanaceae), Senna rugosa (G. Don) Irwin \& Barneby e Chamaecrista debilis (Vogel) Irwin \& Barneby (Caesalpiniaceae).

A coleta de óleo foi observada em flores das seguintes Malpighiaceae: Byrsonima intermedia A. Juss., Banisteriopsis adenopoda (A. Juss.) B. Gates, Banisteriopsis malifolia (Nees \& Martius) B. Gates, Banisteriopsis oxyclada (A. Juss.) B. Gates, Stigmaphyllon lalandianum A. Juss. e Peixotoa reticulata Griseb. Ocorreu sobreposição no florescimento de várias dessas espécies, mas em todo o período de atividade de C. scopipes existiam fontes de óleos florais disponíveis (Fig. 6). Durante as visitas, as fêmeas prendiam-se pelas mandíbulas na quinta pétala e, com as cerdas modificadas dos basitarsos anteriores e médios, raspavam os elaióforos, localizados na base do cálice (Fig. 3). As escopas, em geral, já continham 
pólen antes da coleta de óleo (Fig. 4). Muitas vezes, as fêmeas utilizavam somente os basitarsos anteriores para a raspagem dos elaióforos, o que está relacionado ao pequeno tamanho das flores (4,4 a 8,2 mm de diâmetro do cálice), em comparação com o tamanho corporal da abelha (11,2 $\mathrm{mm}$ de largura e 9,6 $\mathrm{mm}$ de comprimento do tórax).

Fêmeas e machos foram observados em flores de Distictella elongata (Vahl) Urb. e Memora peregrina (Miers.) Sandwith (Bignoniaceae), coletando néctar, de modo legítimo, isto é, entrando pelo tubo da corola.

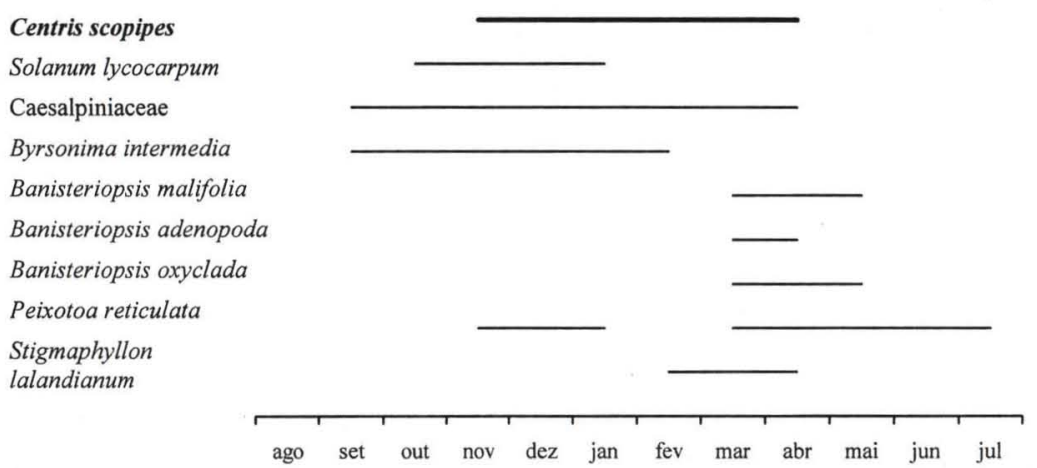

Fig. 6. Atividade de C. scopipes nas flores e florescimento das espécies de Malpighiaceae e algumas fontes de pólen utilizadas por essas abelhas, na E.E. Jataí, Luiz Antônio, São Paulo.

\section{DISCUSSÃO}

As observações apresentadas para Centris scopipes ampliam o espectro conhecido de espécies de térmitas cujos ninhos servem de substrato de nidificação de $C$. (Ptilotopus). Os registros conhecidos até o momento indicam a utilização de termiteiros arborícolas e epígeos construídos por cupins da família Termitidae (Tab. I). No caso de $C$. thoracica Lepeletier, 1841, não há certeza de que pertença ao subgênero Ptilotopus. De acordo com Coville et al. (1983), essa espécie não foi estudada após sua descrição. Esses autores sugerem que pertença ao subgênero Ptilotopus, devido a sua associação com termiteiros, mas LAROCA et al. (1993) consideraram-na como Melacentris e sugerem que a semelhança quanto ao substrato de nidificação seja indicativo de uma proximidade filogenética entre os dois subgêneros.

As duas espécies de cupins em cujos termiteiros foram encontrados ninhos de C. thoracica (Tab. I) pertencem à subfamília Nasutitermitinae, de distribuição neotropical, assim como Procornitermes araujoi, sendo as três espécies características de regiões de cerrado (CONSTANTINO 1999). Os ninhos de P. araujoi são epígeos, assim como de Armitermes euamignathus Silvestri.

Centris derasa e C. sponsa nidificam em termiteiros arborícolas construídos por Microcerotermes Silvestri. Esse gênero de cupins é pantropical e a distribuição das espécies ainda não é bem conhecida (CONSTANTINO 1999). 
Tabela I. Térmitas hospedeiros e abelhas parasitas de Centris (Ptilotopus).

\begin{tabular}{|c|c|c|c|c|c|}
\hline & Térmita hospedeiro & Localidade & Ninho* & Parasitas & Autor \\
\hline C. scopipes & Procornitermes araujoi & SP-Luiz Antônio & Epigeo & Acanthopus excellens & Este trabalho \\
\hline C. sponsa & $\begin{array}{l}\text { Microcerotermes bouvieri } \\
\text { Microcerotermes sp. }\end{array}$ & $\begin{array}{l}\text { PE-Tapéra } \\
\text { GO-Porto Nacional }\end{array}$ & $\begin{array}{l}\text { Arboricola } \\
\text { |Arboricola }\end{array}$ & Acanthopus excellens & $\begin{array}{l}\text { PICKEL (1928) } \\
\text { LAROCA et al. (1993) }\end{array}$ \\
\hline C. derasa & $\begin{array}{l}\text { Microcerotermes arboreus } \\
\text { Microcerotermes arboreus }\end{array}$ & $\begin{array}{l}\text { Trinidad-Curepe } \\
\text { Trinidad }\end{array}$ & Arboricola & $\begin{array}{l}\text { Acanthopus palmatus } \\
\text { Hoplomutilla sp. }\end{array}$ & $\begin{array}{l}\text { BENNETT (1964), } \\
\text { ROZEN 91969) } \\
\text { VESEY-FITZGERALD } \\
\text { (1939) }\end{array}$ \\
\hline C. nobilis & & & & Acanthopus palmatus & DUCKE (1902) \\
\hline C. thoracica & $\begin{array}{l}\text { Armitermes euamignathus } \\
\text { Constrictotermes cyphergaster }\end{array}$ & $\begin{array}{l}\text { MT-Coxipó } \\
\text { MT }\end{array}$ & $\begin{array}{l}\text { Epigeo } \\
\text { Provável } \\
\text { arboricola }\end{array}$ & $\begin{array}{l}\text { Acanthopus palmatus } \\
\text { Acanthopus palmatus }\end{array}$ & $\begin{array}{l}\text { SILVESTRI (1903) } \\
\text { SILVESTRI (1903) }\end{array}$ \\
\hline
\end{tabular}

$\left.{ }^{*}\right)$ de acordo com Constantino (1999); $\left(^{* \star}\right)$ Acanthopus palmatus citado como A. splendidus (para sinonimia de A. palmatus vide MOURE 1960).

A arquitetura dos ninhos de C. scopipes, em relação ao número e disposição das células e à orientação do canal de entrada, é bastante semelhante àquela de $C$. sponsa (PICKEL 1928; LAROCA et al. 1993) e C. derasa (VESEY-FITZGERALD 1939; BENNETT 1964), cujos ninhos são construídos em termiteiros arborícolas. BENNETT (1964) encontrou ninhos de $C$. derasa com duas galerias, a partir de uma mesma entrada, como observado neste trabalho para C. scopipes, embora, segundo aquele autor, a presença de uma única galeria fosse mais comum.

Um mesmo termiteiro pode apresentar mais de um ninho e as células abandonadas de ninhos de anos anteriores são incorporadas a ele. BENNETT (1964) encontrou até 150 células velhas de $C$. derasa em um ninho de Microcerotermes.

Os estágios larvais encontrados indicam que $C$. scopipes constrói inicialmente a galeria de células mais próxima ao canal de entrada, e no sentido ascendente. Talvez o preenchimento da célula superior com terra ocorra durante a escavação da segunda galeria.

As células de cria não são facilmente mantidas em laboratório, a maioria delas tendo sido atacada por fungos. Foi verificado também o ataque de fungos em células nos termiteiros. O único macho criado em laboratório emergiu 11 meses após o aprovisionamento da célula, que ocorreu no final da estação de atividade. Esse fato, associado ao registro do período de atividade dessas abelhas nas flores, sugere que $C$. scopipes possua somente uma geração ao ano (univoltina).

As provisões depositadas nas células de $C$. scopipes apresentam uma camada superior oleosa, inicialmente líquida e que, mais tarde, incorpora-se à massa de pólen, tomando a consistência pastosa homogênea. Observações semelhantes foram feitas para C. derasa (Vesey-FitzGerald 1939) e C. sponsa (PiCKel 1928; LAROCA et al. 1993).

A deposição das fezes entre as finas cutículas do casulo, como observado para C. scopipes neste trabalho, foi reportada para C. (Centris) flavofasciata Friese, 1899 (VINSON et al. 1987), C. (Melacentris) collaris Lepeletier, 1841 (CAMILlo et al. 1993), que nidificam no solo, e C. (Hemisiella) vittata Lepeletier, 1841 (PEREIRA et al. 1999), que nidifica em cavidades pré-existentes. Outras espécies de Centris, pertencentes a diferentes subgêneros e que tiveram sua nidificação estudada, defecam antes de tecer 
o casulo, como é o caso de C. (Trachina) heithausi Snelling, 1874 (Coville et al. 1986), C. (Paracentris) caesalpiniae Cockerell, 1897 e C. (Xerocentris) pallida Fox, 1899 (ROZEN \& BUCHMANN 1990), todas em ninhos no solo.

As fontes de pólen para $C$. scopipes foram espécies de Caesalpiniaceae e Solanaceae, também visitadas na mesma área por $C$. (Ptilotopus) sponsa e $C$. (P.) denudans Lepeletier, 1841. A coleta de pólen feita por vibração é comum entre os Centridini, além de ser considerada basal na evolução das abelhas (BUCHMANN 1983). Em Malpighiaceae, coletam primariamente substâncias oleosas nas glândulas calicinais de espécies de Banisteriopsis, Byrsonima, Stigmaphyllon e Peixotoa. Durante as visitas a essas flores, grãos de pólen das anteras abertas ficam aderidos à região ventral do tórax das abelhas, de onde, mais tarde, são retirados e incorporados à massa de aprovisionamento. Parte da massa de pólen aderida à região dos trocanteres, geralmente não é retirada pela fêmea, e pode servir à polinização.

Dados de literatura apontam outras espécies de Byrsonima, na área do Distrito Federal, como fontes de recursos para C. scopipes: $B$. crassa Niedenzu, $B$. laxiflora Griseb., B. umbellata Mart. ex Adr. Juss. e B. verbascifolia (L.) Rich. ex A.L. Juss. (BARros 1992). A coleta de néctar em flores de Distictella elongata já havia sido relatada por YANAGIZAWA \& GOTTSBERGER (1983), que descrevem o comportamento de visita e polinização das flores por essas abelhas.

As fêmeas de C. scopipes ficam grande parte do tempo em forrageio, permanecendo pouco tempo no ninho, entre cada viagem de coleta. Embora a fêmea de Acanthopus excellens tenha sido observada entrando no canal, na ausência da hospedeira, o tempo gasto no ninho não foi suficiente para a postura. RoZEN (1991) observou que a postura de Acanthopus é feita perfurando o opérculo, após a célula da hospedeira ter sido fechada, o que também explica o comportamento observado, quando a célula estava ainda em fase de aprovisionamento. Em ninhos de $C$. scopipes, é possível que a célula superior, de mais fácil acesso após o fechamento da galeria, seja o alvo principal dos ataques do parasita. No entanto, o seu preenchimento com terra talvez evite a postura pela parasita.

Não existe registro quanto à ocorrência de uma célula preenchida com terra em outros $C$. (Ptilotopus). A presença de uma célula vestibular ou a construção e aprovisionamento parcial da célula mais externa de uma série foi verificada para várias espécies de Centris, e discutida também como estratégia de proteção contra o parasitismo (VINSON \& FRANKIE 1977).

Acanthopus excellens é, pela primeira vez, registrada como parasita de Centris scopipes. Essa espécie já havia sido registrada em ninhos de C. sponsa (PICKEL 1928). Acanthopus palmatus (Olivier, 1789) foi também observada parasitando ninhos de Centris (Ptilotopus) (ver Tab. I). DuCKE (1902) cita ainda $A$. palmatus como o parasita presumível de C. (Ptilotopus) nobilis Westwood, 1840 e Vesey-FitzGerald (1939) menciona que Hoplomutilla sp. seria um parasita freqüente de C. derasa.

Segundo SNELling \& BROOKS (1985) há somente uma espécie no gênero Acanthopus e os outros nomes deveriam ser considerados sinônimos-júniores de $A$. palmatus. Contudo, o exame do material depositado na coleção RPSP permite concluir que se trata de duas espécies distintas. 
AGRADECIMENTOS. A João M.F. Camargo, pelas condições oferecidas no laboratório e acesso aos exemplares de C. (Ptilotopus) e Acanthopus da Coleção RPSP; Eliana M. Cancello, pela identificação de Procornitermes; Sr. Sebastião A. Oliveira e José M. Zanetti pelo auxílio no trabalho de campo; Antonio C. Zanatto pelo apoio logístico na Estação Ecológica Jatai; Fernando C.V. Zanella, pela leitura e sugestões ao manuscrito; Marcio L. Oliveira pelo auxílio no campo e sugestões; a dois revisores anônimos, pelas sugestões apresentadas. A autora é bolsista do CNPq (Doutorado).

\section{REFERÊNCIAS BIBLIOGRÁFICAS}

Barros, M.A.G. 1992. Fenologia da floração, estratégias reprodutivas e polinização de espécies simpátricas do gênero Byrsonima Rich (Malpighiaceae). Rev. Brasil. Biol. 57 (2): 343-353.

Bennetr, F.D. 1964. Notes on the nesting site of Centris derasa (Hymenoptera: Apoidea). Pan-Pac. Entomol. 40 (2): 125-128.

BuCHMANN, S.L. 1983. Buzz pollination in angiosperms, p. 73-113. In: C.E. JonES \& R. J. LitTLE (Eds). Handbook of experimental pollination biology. New York, Academic Editions, Van Nostrand Reinhold Co. Inc., 558p.

Camillo, E.; C.A. Garófalo; J.C. Serrano. 1993. Hábitos de nidificação de Melitoma segmentaria, Centris collaris, Centris fuscata e Paratetrapedia gigantea (Hymenoptera, Anthophoridae). Revta bras. Ent. 37(1): 145-156.

Constantino, R. 1999. Chave ilustrada para identificação dos gêneros de cupins (Insecta: Isoptera) que ocorrem no Brasil. Papéis Avuls Zool., São Paulo, 40 (25): 387-448.

Coville, R.E.; G.W. FrankiE; S.B. Vinson. 1983. Nests of Centris segregata (Hymenoptera: Anthophoridae) with a review of the nesting habits of the genus. Jour. Kansas Ent. Soc. 56 (2): 109-122.

Coville, R.E.; G.W. Frankie; S.L. Buchmann; S.B. Vinson; H.J. Williams. 1986. Nesting and male behavior of Centris heithausi (Hymenoptera: Anthophoridae) in Costa Rica with chemical analysis of the hindleg glands of males. Jour. Kansas Ent. Soc. 59 (2): 325-336.

CURE, J.R.; M. ThiENGO; F.A. SiLveIRA; L.B. RochA. 1992. Levantamento da fauna de abelhas silvestres na "Zona da Mata" de Minas Gerais. III. Mata secundária na região de Viçosa (Hymenoptera, Apoidea). Revta bras. Zool. 9 (3/4): 223-239.

DUCKE, A. 1902. Beobachtungen über Blütenbesuch, Erscheinungszeit etc. der bei Pará vorkommenden Bienen. Allg. Zeitsch. Ent. 20: 417-422.

- 1908. Contribuition a la connaissance de la Faune Hyménoptérologique du Nord-Est du Brésil - II. Hyménoptéres récoltés dans l'État de Ceara en 1908. Rev. d'Entomol. 27: 57-81.

- 1910. Contribuition a la connaissance de la Faune Hyménoptérologique du Nord-Est du Brésil - II. Hyménoptéres récoltés dans l'État de Ceara en 1909 et suppléments aux deux listes antérieures. Rev. d'Entomol. 28 (9-10): 78-122.

GotTSBERger, G. \& I. Silberbauer-GotTSBERger. 1988. Evolution of flower structures and pollination in neotropical Cassiinae (Caesalpiniaceae) species. Phyton 28: 293-320.

Laroca, S.; D.T. Reynaud dos Santos; D.L. Schwartz Filho. 1993. Observations on the nesting biology of three Brazilian Centridini bees: Melanocentris dorsata (Lepeletier 1841), Ptilotopus sponsa (Smith 1854) and Epicharitides obscura (Friese 1899) (Hymenoptera Anthophoridae). Trop. Zool. 6: 151-163.

MARTINS, C.F. 1994. Comunidade de abelhas (Hym., Apoidea) da caatinga e do cerrado com elementos de campo rupestre do estado da Bahia, Brasil. Rev. Nordestina Biol., João Pessoa, 9: 225-257.

Moure, J.S. 1960. Notes on the types of the Neotropical bees described by Fabricius (Hymenoptera: Apoidea). Stud. Entomol. 3 (1-4): 97-160.

NEFF, J.L. \& B.B. SimpSON. 1981. Oil-collecting structures in the Anthophoridae (Hymenoptera): morphology, function, and use in systematics. Jour. Kansas Ent. Soc. 54 (1): 95-123. 
PEDRo, S.R.M. 1996. Lista preliminar das espécies de abelhas (Hymenoptera, Apoidea) que ocorrem na região de Ribeirão Preto e Cajuru, SP. An. Encontro Abelhas, Ribeirão Preto, 2, p. 248-258.

Pereira, M.; C.A. Garófalo; E. Camillo; J.C. Serrano. 1999. Nesting biology of Centris (Hemisiella) vittata Lepeletier in southeastern Brazil (Hymenoptera, Apidae, Centridini). Apidologie 30: 327-338.

PiCKel, B. 1928. Contribuição para a biologia de Centris sponsa e Acanthopus excellens (Hymen.). Bol. Biol., São Paulo, 14: 135-143

REBÊLo, J.M.M. 1995. Espécies de Anthophoridae (Hymenoptera, Apoidea) e sua associação com flores, numa área restrita da ilha de São Luís-MA, Brasil. Bol. Mus. Paraense Emilio Goeldi, Sér. Zool., 11 (2): $105-124$.

Rozen JR., J.G. 1969. The larvae of the Anthophoridae (Hymenoptera, Apoidea). Part 3. The Melectini, Ericrocini, and Rhathymini. Amer. Mus. Novitates 2382: 1-24.

- 1991. Evolution of cleptoparasitism in Anthophoridae bees as revealed by their mode of parasitism and first instars (Hymenoptera: Apoidea). Amer. Mus. Novitates 3029: 1-36.

Rozen JR., J.G. \& S.L. BuChMAnN. 1990. Nesting biology and immature stages of the bees Centris caesalpiniae, C. pallida, and the cleptoparasite Ericrocis lata (Hymenoptera: Apoidea: Anthophoridae). Amer. Mus. Novitates 2985: 1-30.

Sil.veira, F.A.; L.B. Rocha; J.R. CURE; M.J.F. Oliveira. 1993. Abelhas silvestres (Hymenoptera, Apoidea) da Zona da Mata de Minas Gerais. II. Diversidade, abundância e fontes de alimento em uma pastagem abandonada em Ponte Nova. Revta bras. Ent. 37 (3): 595-610.

Silveira, F.A. \& M.J.O. CAmpos. 1995. A melissofauna de Corumbataí (SP) e Paraopeba (MG) e uma análise da biogeografia das abelhas do cerrado brasileiro (Hymenoptera, Apoidea). Revta bras. Ent. 39 (2): 371-401.

Silvestri, F. 1903. Contribuzione alla conoscenza dei Termitidi e Temitofili dell'America meridionale. Redia 1: 1-234.

SNelling, R.R. \& R.W. Brooks. 1985. A review of the genera of cleptoparasitic bees of the tribe Ericrocini (Hymenoptera: Anthophoridae). Contrib. Sci. 369: 1-34.

Vesey-Fitzgerald, D. 1939. Observations on bees (Hymenoptera: Apoidea) in Trinidad, B.W.I. Proc. Royal Ent. Soc. London (A) 14: 107-110.

Vinson, S.B. \& G.W. Frankie. 1977. Nests of Centris aethyctera (Hymenoptera: Apoidea: Anthophoridae) in the dry forest of Costa Rica. Jour. Kansas Ent. Soc. 50 (2): 301-311.

Vinson, S.B.; G.W. FrankiE; R.E. Covil.te. 1987. Nesting habits of Centris flavofasciata Friese (Hymenoptera: Apoidea: Anthophoridae) in Costa Rica. Jour. Kansas Ent. Soc. 60 (2): 249-263.

VogEL, S. 1974. Ölblumen und ölsammelnde Bienen. Trop. und Subtrop. Pflanzenwelt. 7. Wiesbaden, Steiner.

Yanagizawa, Y. \& G. GotTsberger. 1983. Competição entre Distictella elongata (Bignoniaceae) e Crotalaria anagyroides (Fabaceae) com relação às abelhas polinizadoras no cerrado de Botucatu, estado de São Paulo, Brasil. Portug. Acta Biol. (A) 17: 149-166.

ZANELLA, F.C.V. 2000. The bees of the Caatinga (Hymenoptera, Apoidea, Apiformes): a species list and comparative notes regarding their distribution. Apidologie 31: 579-592.

Recebido em 13.VII.2000; aceito em 19.VI.2001 